\title{
AN EVALUATION OF HOUSING FLEXIBILITY AFTER SEVEN YEARS OF HABITATION: IBA HAMBURG 2013
}

\author{
Blerim LUTOLLI (1D* \\ Bauhaus Universität Weimar, Weimar, Germany \\ Received 05 March 2021; accepted 05 November 2021
}

\begin{abstract}
Flexibility in housing has been used for a long time to meet the changing needs of inhabitants. After a century of vicissitude, flexibility became a means for architects to deal with social changes in the new millennium. The International Building Exhibition (IBA) 2013, which took place in Hamburg, Germany, is an example of how the concept of flexibility is being adopted. Housing, in particular, the post-occupancy phase, has not been studied, despite the urban-level aspects of the IBA Hamburg having been extensively written about. Seven years after its construction, nothing is known about what happened regarding these new approaches. The purpose of this study is to investigate the number of households in the IBA Hamburg housing projects that have used the promoted concept of flexibility, particularly in the "Building Exhibition within the Building Exhibition." As a result, this article aims to shed light on this issue by presenting data from a field survey regarding whether floor plan flexibility was used, and if so, to what extent and what were the reasons. As a result, the author utilized an administered and self-administered open and closed-ended survey questionnaire research approach to collect necessary data for the execution of this investigation. The survey was conducted in twenty-two apartments, with four residential buildings chosen as a case selection for this investigation. The results of this study revealed that, despite being considered during the initial planning phase, flexibility was not commonly applied in the housing projects of IBA Hamburg 2013. Furthermore, the findings reveal that the extent of use of flexibility in these case studies is closely linked with the occupation status of the inhabitants.
\end{abstract}

Keywords: IBA Hamburg, housing, flexibility, smart houses, social changes, building exhibition.

\section{Introduction}

On 16 November 2015, Uli Hellweg, director of IBA 2013 Hamburg, presented a speech in Warsaw, explaining the main concepts behind housing projects of IBA Hamburg 2013. Besides addressing the housing issues of the time, Mr. Hellweg referred to the IBA's effort to continue the experimental tradition of earlier building exhibitions, such as Weissenhofsiedlung in 1927 in Stuttgart, through which he highlighted defining characteristics, for example, the use of smart materials, prefabrication and floor plan flexibility. To address this last point, the flexible floor plan projects from Le Corbusier and Jeanneret, in Weissenhofsiedlung, were presented and discussed. Therefore, Hellweg displayed that, though IBA Hamburg was a continuation of previous German building exhibitions, it addressed the social, urban and architectural issues of its time.

Considering Germany's social changes, flexible forms of housing that adapt a living space for expanding and shrinking households are needed (Vallenthin et al., 2010).
In this context, housing flexibility is becoming increasingly important as a means of adapting to demographic change (Wuttke et al., 2018). Furthermore, the difference between individual lifestyles makes the issue even more challenging to predict regarding how people want to live in the future (Jonuschat, 2012). To serve this end, in terms of housing, IBA Hamburg 2013 demonstrates how future housing can be green, affordable and flexible. However, despite its importance, the adoption of housing flexibility principles, particularly in the post-occupancy phase, has remained infrequent and seldom studied. It is a promising area for investigation (Paris \& Lopes, 2018). In the context of this study, the literature review reveals there are no studies concerning the extent of use of flexibility in the post occupancy phase for the IBA 2013, or the flexible housing in the German level context. Hence, research shows that one of the latest studies regarding this aspect was conducted during the 1970s (Institut für Bauforschung, 1980). Several attempts to study IBA Hamburg 2013 consist only of

*Corresponding author. E-mail: blerim.lutolli@uni-weimar.de 
the urban level, such as the work of Chamberlain (2020), Eckard (2017), Geipel (2014) etc., while publications about the housing of IBA 2013 Hamburg, are almost nonexistent and that few are primarily framed into the overview and descriptions of the projects. As maintained further by Braide Eriksson's (2016) studies, a focus on flexible housing related to social changes and residential usability is rare. Housing flexibility is significant not only for IBA Hamburg, but also for other international housing developments. In this context, the purpose of this research paper is to investigate the housing flexibility usage in IBA Hamburg "Building Exhibition within the Building Exhibition," or more precisely, to discover if these flexible housing has been changed in the floor plan by the residents. Moreover, it investigates and presents the main reasons residents implement these changes. The methodology of this research is based on field survey observations using administered and self-administered questionnaires with the residents.

This paper is comprised as follows: section 1 discusses the research background, the importance of housing flexibility, the background of the IBA concept and the ideology of its development, and the IBA Hamburg "Smart Houses," which establish the theoretical framework for the four case studies presented with text and accompanying building images and floor plans; section 2 describes the methodology chosen for the survey of four case studies; section 3 presents the findings of the field survey of the four case studies; and the last section draws relevant conclusions and discussions based on the findings.

\section{Research background}

\subsection{The meaning and the importance of housing flexibility}

Housing represents more than the necessity for shelter (Salama et al., 2017). Since the turn of the century, rapid social changes of the time, such as lifestyle, demographic and cultural changes, brought the demand for flexible housing to the fore. Flexibility is nature's fundamental way of adapting to changing circumstances (Gharavi Alkhansari, 2018, p. 120). In the past two decades, flexibility in housing had become a planning goal and was promoted as an essential benchmark for assessing the quality of housing efforts (Loch, 2011). Furthermore, nowadays, providing more than one choice of housing floor plan may increase residents' spatial control and improve their well-being (Veitch \& Gifford, 1996). Employing flexibility in housing has many benefits as it addresses the issues of finance (flexibility is more economic in the long term), the issue of participation (flexible housing encourages user involvement), technology (the ways that flexible housing exploits advances in construction technology) and use (flexible housing adapts to different usage over time) (Schneider \& Till, 2005). Considering its benefits, flexible housing presents an opportunity for users to participate in the design of their dwelling and to arrange their living spaces according to their lifestyles and needs (Raviz et al., 2015).
The topic of flexible housing has been the subject of much research and studies due to its importance. According to Schneider and Till (2005), flexible housing means designing for choice in terms of social use and construction, or designing for change over its lifetime. According to Hill (2003), flexible housing refers to changing relationships between the use of space, events and context. Eldonk and Fassbinder (1990) maintain that flexible housing means designing domestic architecture at an abstract level, which can be adapted in response to the dynamic process of habitation. Another definition of flexible housing is provided by Hamdi (1990), who believes that housing flexibility refers to the freedom to choose among options that fit individual needs, whether for construction, finance, ownership or management. From this review on housing flexibility, it can be understood that there is one trait that all these definitions share: the ability to modify physical space to adapt to residents' changing needs. Furthermore, regarding benefits that arise from flexibility, the aforementioned authors are even more in agreement.

\subsection{The IBA concept}

The history of the IBA dates from 1901 when the first exhibition was held in Darmstadt, Germany. Since then, it has always introduced a new approach to architecture and the city. Among these last two, the social aspect has always been an element of each IBA event, with its own focus of combating pressing issues from the time that it was launched. Therefore, while "Interbau Berlin 1957" concerned with new forms of housing, the "IBA 1987" in Berlin dealt with urban renewal. "IBA Emscher Park 1999" and "IBA Fürst-PücklerLand 2010" on the other hand concerned the post-industrial territory, embracing new social, and cultural and ecological concepts. "IBA 2010, urban redevelopment of Saxony" focused on the new perspectives for cities in transition, and the IBA Hamburg 2013 intended to address the most pressing issues facing modern cities, which was how cities can continue to grow in a social and ecological way. Hence, one of the most common themes explored in IBA exhibition events (one could compare the housing development of Interbau 1957, or IBA Berlin ' 87 ) is the concept of flexibility that has been used as the main concept in housing. The idea of the IBA is, thereby, linked to its intention to contribute to social progress (Eckardt, 2017). In this context, IBA Hamburg, which took place in the district of Wilhelmsburg, Veddel, and in the inland port of Harburg, represents the largest event in both the number of building projects and the available budget (IBA Hamburg, 2014). Furthermore, as maintained by Geipel (2014), it represents the most important building exhibition of the twenty-first century.

\subsection{IBA Hamburg and its "Smart Houses"}

According to Hellweg (2013a), the director of IBA Hamburg, "upgrade without displacing" and "living means staying" were two fundamental principles of this IBA to avoid gentrification and to support the multiculturality of 


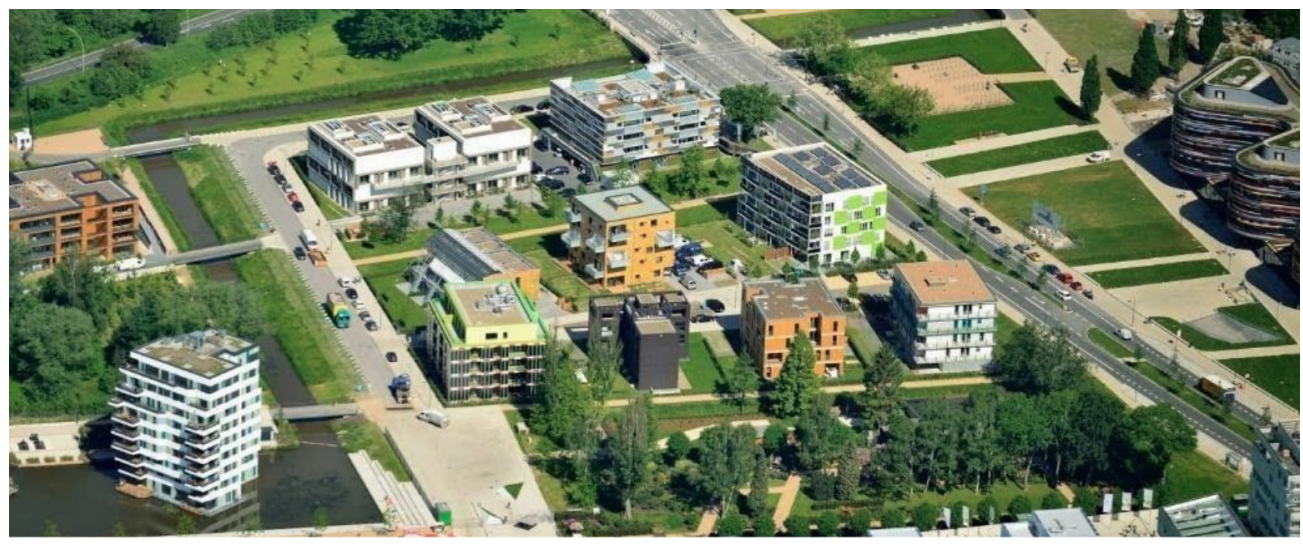

Figure 1. Aerial view of permanent exhibition of IBA 2013 (source: Zillerplus Architekten und Stadtplaner, München)

the Wilhelmsburg district. Within these two principles, three main themes were launched: "Cosmopolis," "Cities and Climate Change" and "Metrozones." The three themes, and in particular, "Metrozones," aimed to bring new solutions for living and working at a micro and macro-level within the city. Within this section, four modules were developed with the purpose of aiming to deal with the sustainability, affordability and personalization of housing based on resident's needs. These were: the "Smart Material House" (using intelligent building materials of the future, allowing buildings and facades to react to change); the "Smart Price Houses" (demonstrating low-cost buildings); the "Water Houses" (using concepts with and on water); and the "Hybrid Houses" (adapting to the requirements of future residents).

Dealing with the issues raised by the IBA Hamburg for all four modules, flexibility in floor plans was an inherent part of the design process. Therefore, architects and engineers experimented with new materials and flexible floor plans (IBA Hamburg, 2013). In this context, flexibility was intended to enable apartments to be internally divided into smaller or larger rooms based on a family's needs, or even left neutral and undetermined in function suitable for commercial space usage (Schoof, 2013). The 15 free-standing buildings in the "Building Exhibition within the Building Exhibition" encompass the four aforementioned modules, recognizable under the one unified name: "Smart Houses" (Figure 1).

\section{Research methodology}

The aims of the research of this study are accomplished using a quantitative research approach with a field survey research design as a data collection methodology. Research methods are selected based on their suitability to achieve each research objective. This study uses a case study survey research approach to gather data about subjects consistent with the households of the apartments. The collected data aims to gather information regarding the number of households in the IBA Hamburg housing projects that used the promoted concept of flexibility.
The quantitative survey subjected participants to close and open-ended questions, allowing them to contribute their thoughts to a specific range of answers. Out of the 22 projects in the "Building Exhibition within the Building Exhibition", four residential buildings were chosen as a case study. The major criterion for selecting these case studies was that they possessed flexibility as a common factor and the ability to change to meet the residents' changing needs. Other residential buildings that did not emphasize flexibility were excluded from this study. This study used administered and self-administered questionnaires with open and closed-ended questions in terms of survey methodology. Because of the COVID-19 situation, self-administered surveys were only used in cases when respondents refused or were unable to meet in-person. The questionnaire was designed to be short, simple and concise. The questionnaire employed a quantitative approach to collect only the required information, such as the number of floor plan changes made in the apartment and the main reason for these changes. The method used for the data collection is designed to ensure that the elicited data remain within four points:

- The time span they have been living there.

- Their occupancy status.

- The number of changes to their apartments that have been made so far (if any).

- The main reasons behind these changes.

In this study, the explanatory case study is used for data collection and validating the results. Using the explanatory case studies, the author inspected the collected data thoroughly at a surface and deep level to find the explanation of the phenomena in the data. A brief description of the selected cases is described in the next section.

\subsection{Case studies}

From the 60 plus building projects that were built under the IBA Hamburg (Walter, 2014) from different disciplines, this research is concentrated on the "Building Exhibition within the Building Exhibition" located in Neue Mitte Wilhelmsburg, which, according to Hellweg (2013b), are meant 
to showcase residential concepts which embody the IBA main housing concepts, relevant to the metropolis of the twenty-first century. Based on the IBA Hamburg (2014), the projects on this permanent exhibition reveal the limitations of innovation in standard German housing construction. Therefore, out of 22 projects that the "Building Exhibition within the Building Exhibition" in Neue Mitte Wilhelmsburg contains, four residential housing projects were chosen for study. The reason for selecting these case studies was based on determining those that stand out and were celebrated under the flexibility concept. The main notion behind four case studies was the flexibility to enable residents' imprint and inclusion in the post-occupancy phase. Hence, other residential buildings of IBA Hamburg where flexibility was not the main concept were excluded from this research. These four projects are part of the modules from "Smart Material House" (the projects such as "Smart is green" and "Woodcube") and from the module "Smart Price Houses" (the projects "C.S. \# 1" and "CSH"). Information regarding these four selected projects was collected from available literature, discussions with respective architects of the projects and, most importantly, visiting the housing projects as part of the field survey.

\subsubsection{Case study 1 , "Smart is green"}

"Smart is green" is one of the four projects from the module "Smart Material House." shown in Figure 2. This multi-storey apartment block on five levels, was designed by "Zillerplus Architekten und Stadtplaner" based in Munich. It comprises 14 apartments, three on each floor. The architects of the project explained that the project was based on three main essential features: the development of new efficient materials, energy generation and flexible floor plans (Ziller, 2020).

According to the architect, the floor plans can be changed according to the individual needs of the residents; therefore, allowing the residents to adapt their apartments to their current lifestyles. Moreover, this allows the building to be adapted to address technological changes and developments or even economic changes, for example, by being subdivided and sublet after children move out

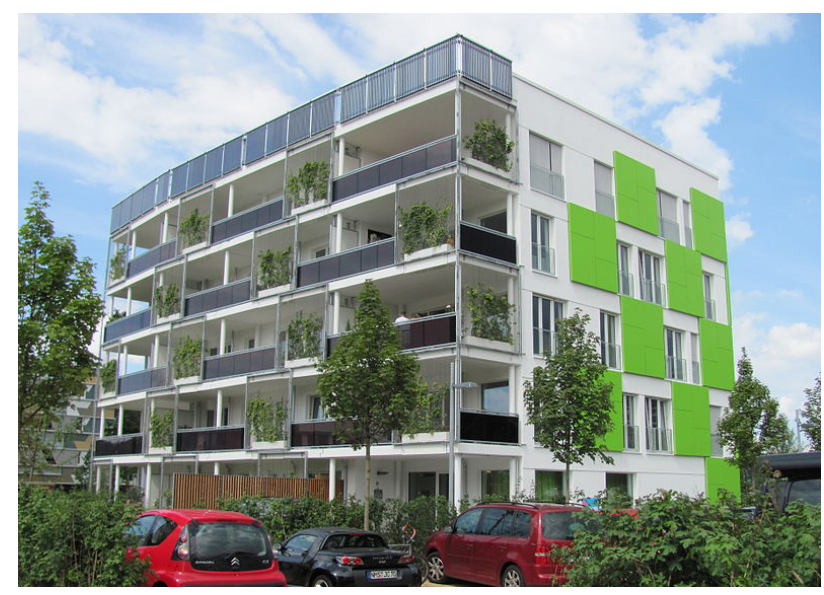

Figure 2. "Smart is green" (source: Wikimedia Commons)

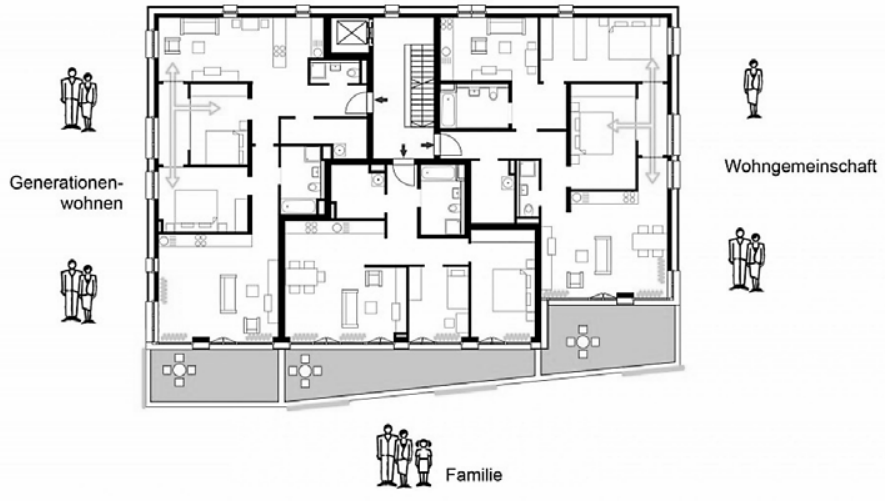

Figure 3. "Smart is green" Floor plan flexibility, scenario A (source: zillerplus Architekten und Stadtplaner, München)

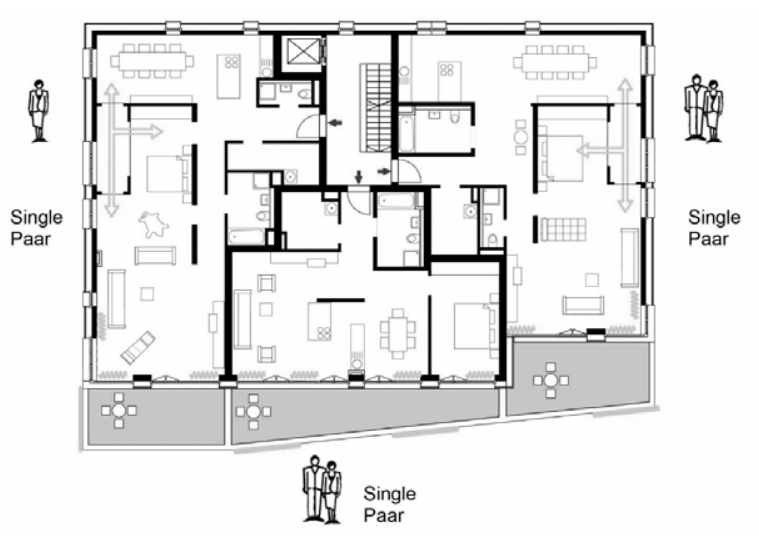

Figure 4. "Smart is green" Floor plan flexibility, scenario B (source: zillerplus Architekten und Stadtplaner, München)

(Hacker \& Lanz, 2013). In this context, the position of the staircase allows further access to the apartment to accommodate flexible floor plans for couples, single-shared apartments, families in changing life situations and people of all ages, shown in Figure 3 and Figure 4.

\subsubsection{Case study 2, "Woodcube"}

The "Woodcube" is the second of the four projects from the module "Smart Material House" shown in Figure 5. This five-storey timber prefabricated residential building, located in the heart of the exhibition site was designed by the "Institut für urbanen Holzbau - IfuH" in Berlin, and comprises eight apartments, ranging from 70-190 square meters. The main concept behind this residential building is based on the sustainable and passive approach, low cost and flexibility in the floor plan. Significant attention was paid to technical details with the aim to enable residents to adopt changes. The ceiling joists are positioned to take into consideration whether a modification or even an extension is needed, making the apartments suitable for adaptation at any time, if required (Petersen \& Roedel, 2014). This enables the floor plans to allow for flexible layout and use. Another feature that enables flexible use is the large spans between load-bearing walls, which enable different scenarios to be reached within the floor plans (Figure 6). 


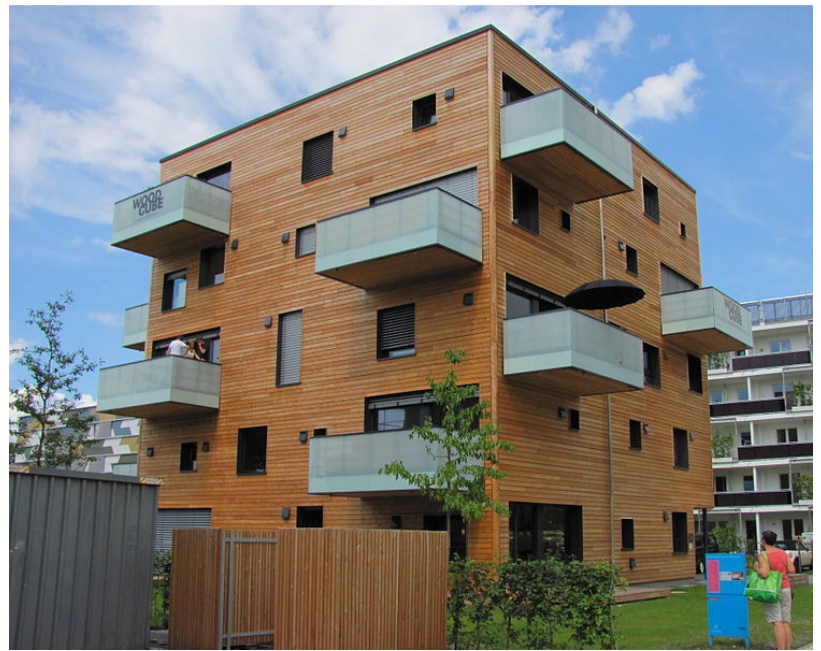

Figure 5. "Woodcube" (source: Wikimedia Commons)

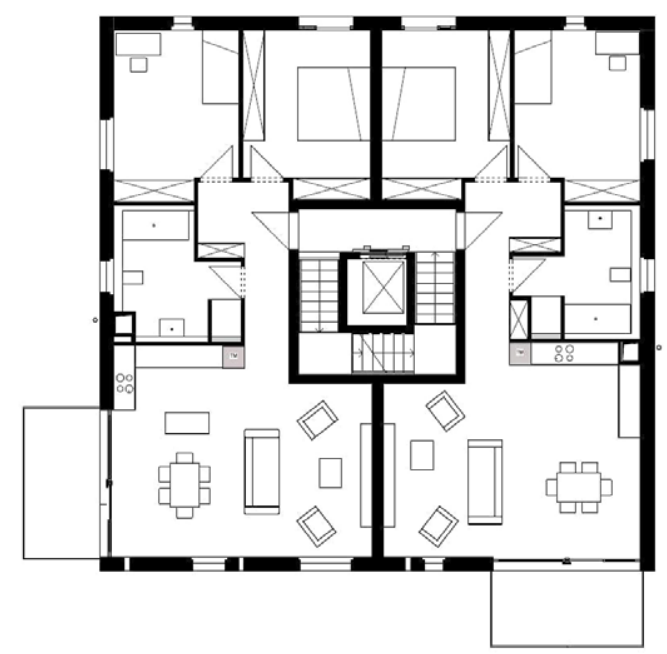

Figure 6. Typical floor plan of "Woodcube" (source: Architekturagentur, Stuttgart)

\subsubsection{Case study 3, "C.S. \# 1"}

The module "Smart Price Houses" includes "C.S. \# 1" among three other projects shown in Figure 7. Designed by "Fusi and Ammann Architekten" in Hamburg, this multi-storey apartment block comprises six apartments, ranging from 45-140 square meters. It consists of a modular assembly system based on a high degree of prefabrication, that can be constructed quickly and cost-effectively. Designed as a " $T$ " shape, aiming to be suitable for different urban context settings (perimeter development, freestanding, etc.) based on IBA 2013 (Petersen \& Roedel, 2013) the building is also extremely flexible in its floor plan, leaving room for residents to express their individuality, and to allow space to meet their many and changing needs. Such a flexible approach is met through modules. Each floor has four modules, 45 square meters each, which, due to the central position of the service block within the module, can be freely merged, vertically or horizontally, in countless different ways shown in Figure 8. As noted further by the IBA Hamburg (2014), Fusi and Ammann

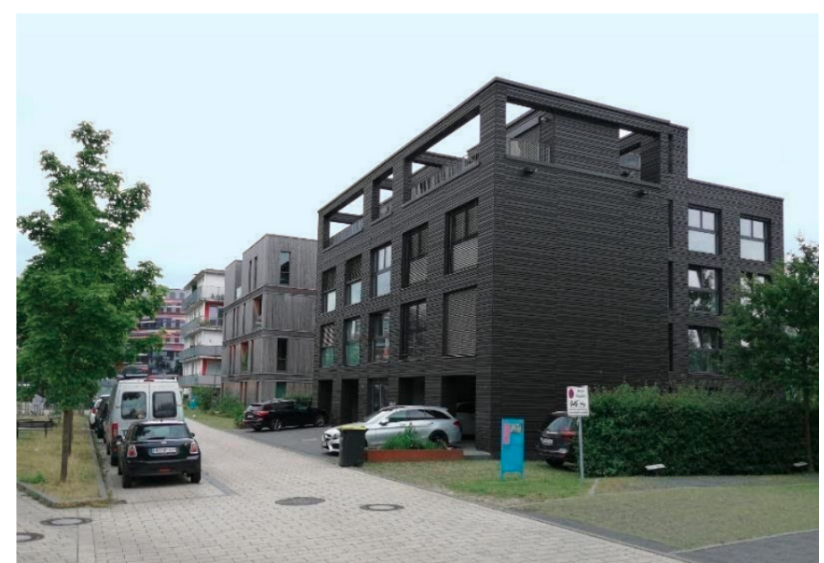

Figure 7. Street view of “C.S. \# 1" (source: Author)

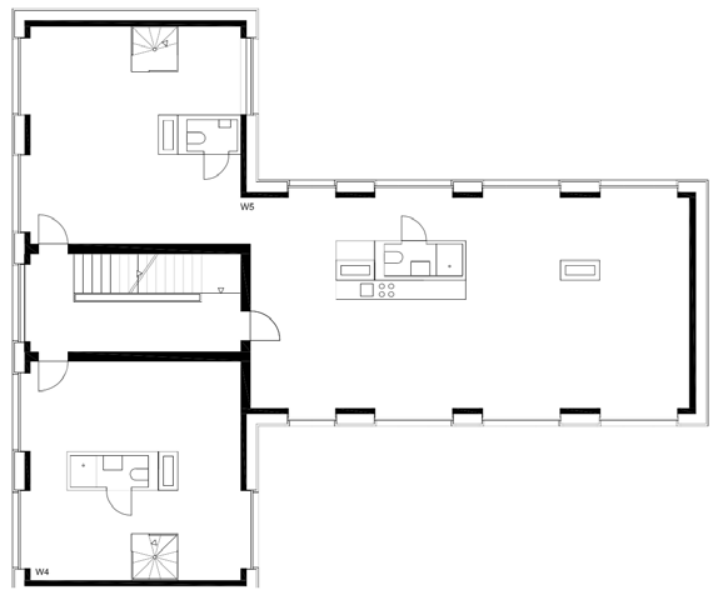

Figure 8. Flexible and open floor plan of "C.S. \# 1" (source: Fusi \& Ammann Architekten, Hamburg)

Architekten created a concept that interprets the "townhouse" as a flexible loft apartment building that can be adapted to the living situation and wishes of its residents.

\subsubsection{Case study 4, "CSH"}

Designed by "Adjaye Associates" in London and realized by "Planpark Architects", the multi- storey housing "CSH" consists of eight apartments, ranging from 47-124 square metres shown in Figure 9. The project features solid wood components, low resources consumption and flexibility. Regarding the last, the unit modules consist of easy assembling modules using prefabricated components. The apartment kit modules can be joined vertically to other units forming maisonettes, or horizontally with adjacent apartments. This enables individual arrangements of apartments at different sizes for different and changing social needs of families, or even integrating a home office (IBA Hamburg, 2014). In this context, it is the large span of the load-bearing walls that allows for a flexible configuration of the floor plans shown in Figure 10. 


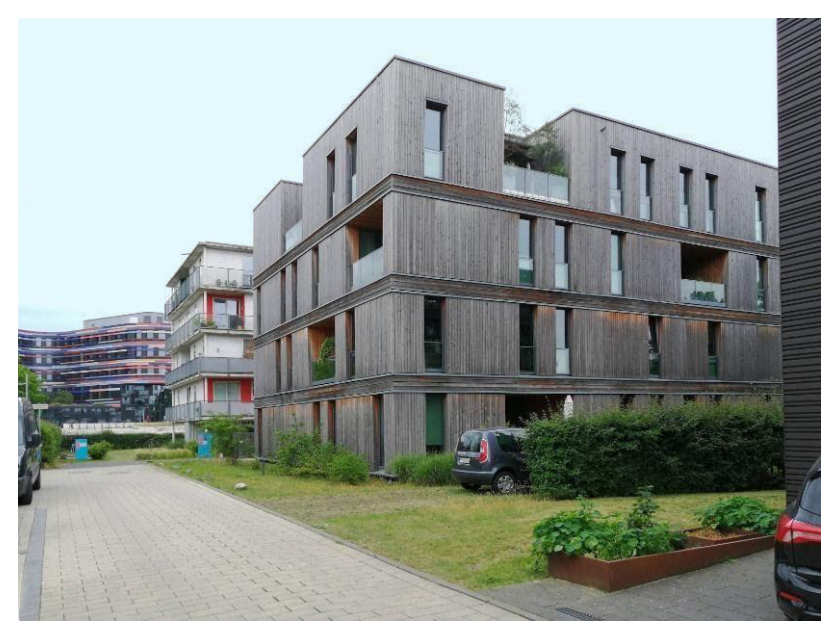

Figure 9. Street view of “CHS” (source: Author)

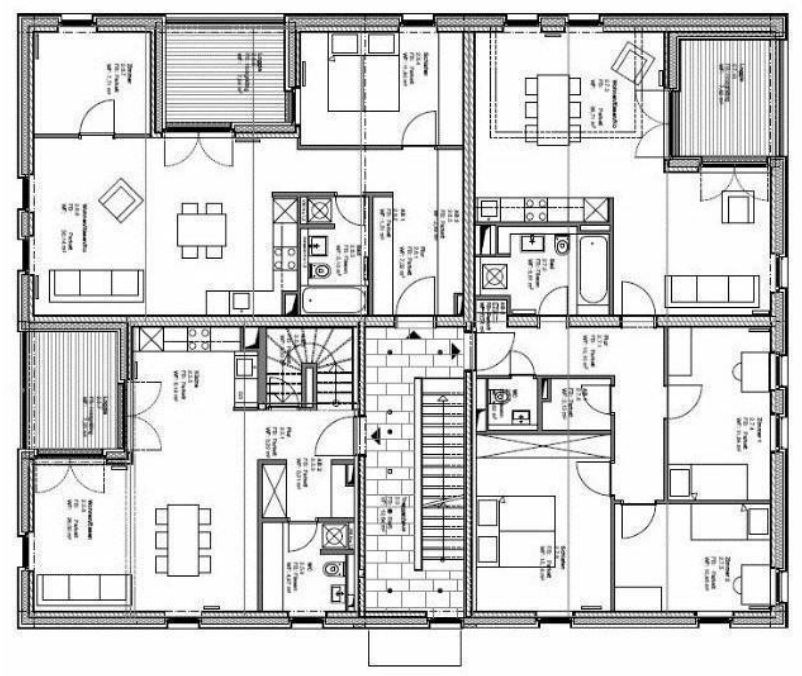

Figure 10. Floor plan of "CHS” (source: Planpark Architekten)

To design the research plan, this research chose the guidelines proposed by Wohlin and Aurum (2015). Figure 11 shows the research structure split into three phases with eight decision points. In addition, different methods can be used to execute each decision point.

As a result, this work used Wohlin and Aurum's guidelines and mapped the research decision-making process of the research design with the research structure shown in Figure 12.

This study aims to investigate the number of inhabitants in IBA Hamburg housing projects who have used the promoted concept of flexibility, particularly in the "Building Exhibition within the Building Exhibition." This study aims to contribute a specific problem of flexibility; therefore, this research has used applied research for the outcome of this study. This research has used deductive methods for research logic. Deductive reasoning is a topdown approach that works from more general to specific. This approach involves the construction of a theory, identifying the case studies from that theory, and then collecting and evaluating data to achieve research objectives.

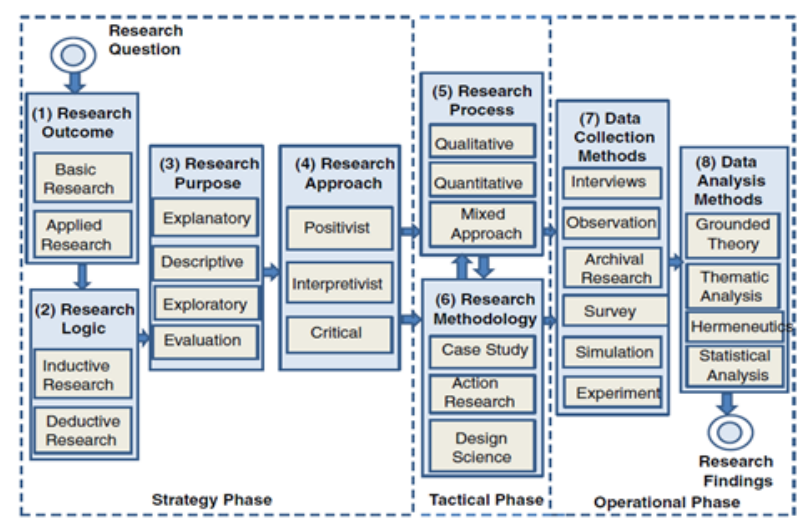

Figure 11. Research structure (source: Wohlin \& Aurum, 2015)

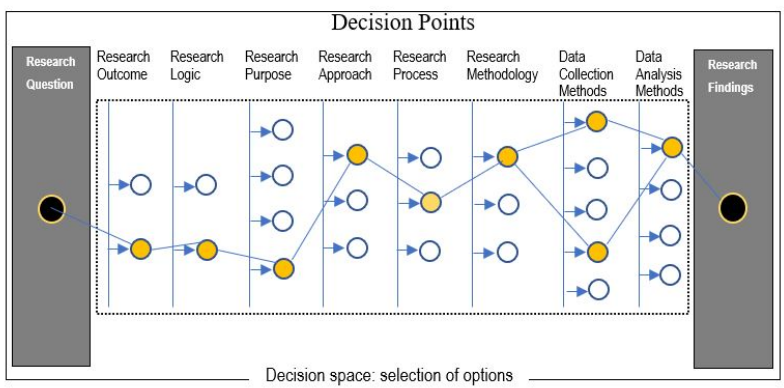

Figure 12. Research decision-making process (source: Author)

This research starts with problem identification through detailed literature investigation, and is evaluated after data collection. The purpose of this research is to evaluate the number of households in the IBA Hamburg housing projects who have used the promoted concept of flexibility. The positivist research approach is used as it requires an objective approach and meaningful results.

To extract the necessary data and conclusion, these points must be correlated to one another. The concept of the questionnaire used in this study is shown in Figure 13. The relationship between the length of time spent in a space and the number of changes, for example, allows us to estimate the scale of changes over time. For example, if there is a difference in the scope of changes between owners and tenants, the correlation between the number of changes and the residents' occupancy status will reveal it. All four questions aim to give a clear picture of the extent of these changes, the role of a tenant or owner when faced with these changes and the primary reasons for these changes. In cases when administered questionnaires could not be used, a semi-open interview with the household heads was conducted as a second form of the survey. As a result, the goal was to determine the most profound challenges to making or not making changes to their floor plan layout. The semi-open interviews were held after receiving the filled questionnaire. Two attempts were made to conduct the interview at the front door. The author was aware of the importance of being careful while posing questions to avoid any suggestive questions that can lead to confusing responses from the respondents. 


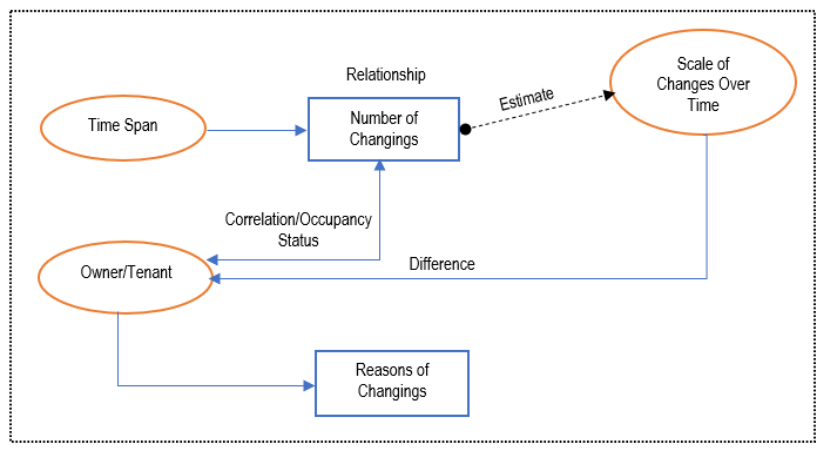

Figure 13. Questionnaire framework (source: Author)

The term flexibility is used in this study to refer to the concept of flexibility as described by the IBA Hamburg, which is the ability to physically adapt or change the floor plan configuration to meet various lifestyle changes of residents. According to Hellweg (2015), IBA flexible buildings are designed to adapt to the changing needs and demands of users in today's society. Since users' demands could have a wide range of meanings, this study does not confine the term "flexibility" to the domain of lifestyle. As a result, the research from the field survey and questionnaires will determine if there are any other factors that result in the residents' usage of flexibility. The analyses of the four case studies will display the extent of use of flexibility so far by the residents. This study aims to determine whether any of the apartments have been changed, quantify the number, duration and determine the primary reasons for these changes. Therefore, given the significant work and time required to keep track of the changes, this study does not investigate the manifestation of residentmade changes to the floor layout. These findings will fill a gap in the present literature on flexible housing and pave the way for further research into how these changes in the floor plan were implemented.

\section{Results and discussions}

Out of the 36 apartments that the four case studies encompass, the survey is conducted for 22 of them, which equates to approximately $60 \%$. For the other 14 apart- ments, interview with the households was not possible either because of reluctance to be interviewed or they were not in the apartment within these two attempts of the survey. As can be seen in Table 1, in the case study 1 ("Smart is green") out of 14 apartments, nine are surveyed, in case study 2 ("Woodcube") out of eight, four were surveyed, in case study 3 ("C.S. \# 1") out of six, five were surveyed, and in case study 4 ("CSH") out of eight, four were surveyed.

Concerning the extent of changes that apartments underwent, Table 1 further shows that out of the 22 surveyed apartments, only six underwent changes (this is equivalent to $22 \%$ of the apartments). Observing the changes that happened in these apartments survey shows that these were of two types: minor, such as removing or adding a partition wall to reconfigure the living space; and major: combining or even splitting up different room spaces (increasing or reducing the number of rooms). In this context, the findings reveal that in two of these apartments, there were only minor changes, while the other four apartments featured major changes.

Concerning the time these changes happen and what they consist of, the survey shows that these changes happen at different times made for different reasons, which resulted in different forms of changes varying from minor to major ones, as explained. Hence, for example in the "Smart is green" apartment was changed in 2013 and consisted of putting a new partition wall between the kitchen and the living room. The change in the second apartment happened after five years of occupancy in 2018, which consisted of making a new partition wall in the living room aiming to create a semi open space which can be used for either sleeping or working space. In "Woodcube" the only changed apartment made by the second household happened in 2019, four years after their occupancy. It consisted of making a small new bedroom room within the living room. In "C.S. \# 1", on the other hand, the only change that happened after the five years of occupancy in 2018 consisted of separating two small apartments together vertically, which used to be a duplex of two stories since 2013. In case study four, "CSH", one apartment was changed in 2017 and consists of joining two rooms together, from being a three room apartment into a two one. The second apartment was changed just recently in

Table 1. The number of surveyed apartments (source: Author)

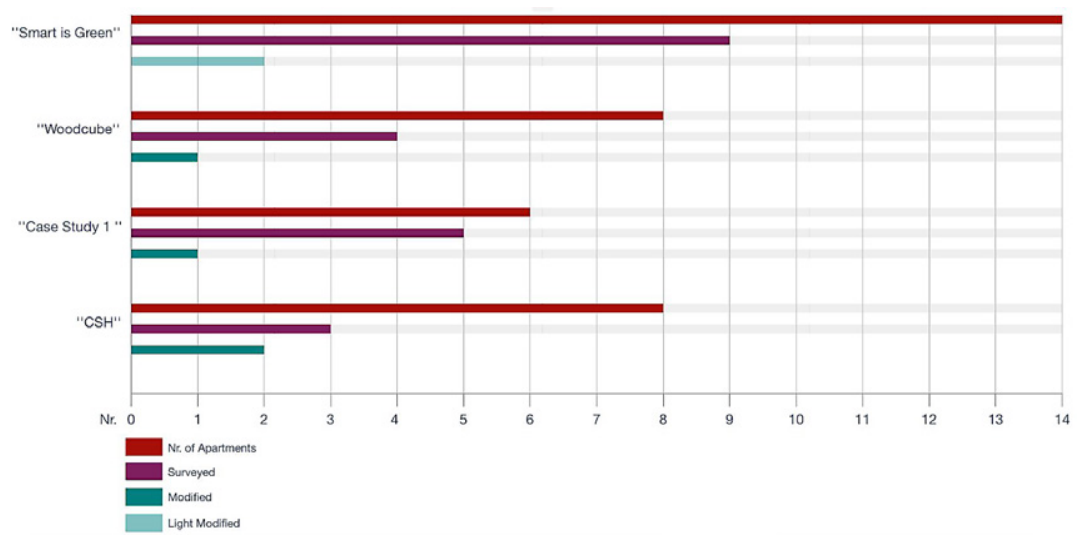


Table 2. The number of owned and leased apartments (source: Author)

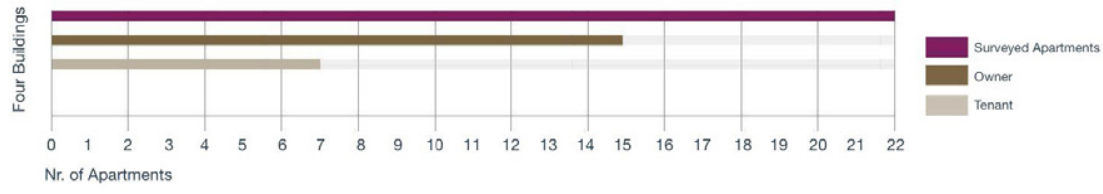

Table 3. The number of changed apartments according to the occupancy status of the residents (source: Author)

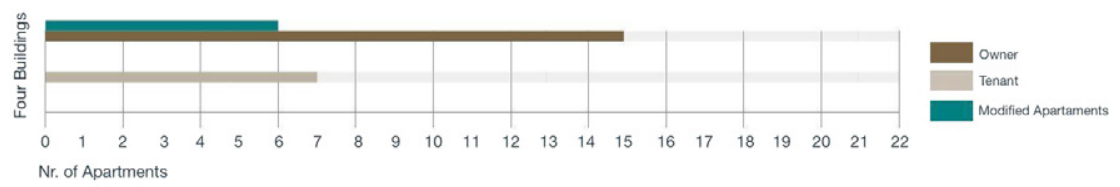

2020 and consisted of adding a small bedroom within the living room.

An important consideration regarding this quantity of changes is whether the occupants of the apartments are owners or tenants. In this context, the ratio between owners and tenants is presented in Table 2. Research shows an interesting fact whereby all changes occurred in owned apartments and none of them in rented apartments as shown in Table 3 . This suggests that owners are concerned more with flexibility when they are owners of apartments rather than when they are a tenant.

Looking toward determining the reasons for these changes, the survey shows that these alterations happen for different reasons, such as a small demographic difference between lifestyle and economic reasons as shown in Table 4. For example, in "Smart is green", the two noted changes in two different apartments are made due to the lifestyle and demographic changes. The former consists of adding a partition wall between the kitchen and living room, while the second creates a new semi-open room for sleeping and working. In "Woodcube", the new small room added within the living room was made due to the demographic changes of the family. In "C.S. \# 1", the separation of the duplex into two small apartments was made due to the economic situation of the household. Since the apartment was too sizable, the family kept one for themselves and leased the second one to someone else. In "CSH", the two noted changes in two different apartments were made due to demographic and economic reasons. The former apartment was changed after a member of the family moved out; therefore, the household joined two rooms together and made a single large one. The second

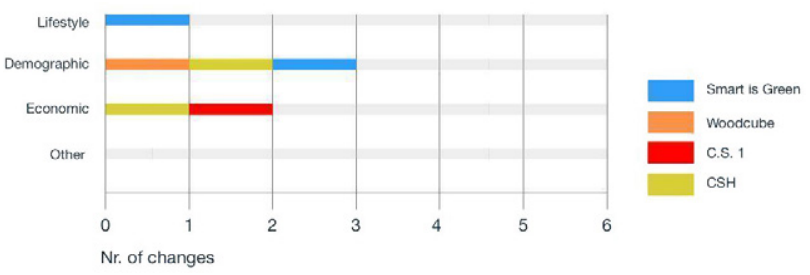

Table 4. The reasons behind the changes in apartments (source: Author) apartment was changed just recently in 2020 and consisted of adding a small bedroom leased to a remote worker.

A review of the collated results shows that flexibility is used less extensively during the last seven years these exhibitions have been in existence. This could be because of several reasons. Firstly, in the majority of cases, residents were not an integral part of the housing process. Most apartments were sold to prospective buyers as an end product (letting them only have an imprint over their living space in the post-occupancy phase). The participation process plays an important role in regard to giving residents the feeling of possession. Secondly, in the semi-open interview, it is found that those occupants who were tenants expressed hesitation to undertake changes in their apartments, even in cases where changes are expressly needed. This occurs because of a lack of encouragement from the owners of these apartments. Therefore, this could be the main reason why none of the tenants have undertaken changes so far. Moreover, in the semistructured interview with tenants, the majority of them would prefer to move out of their apartments rather than undertake changes. This is because, in case of moving out, the apartment must reverse into the initial form and this costs a considerable sum. Thirdly, with regard to external factors, the use of technological prefabrication methods in the housing units might have been another reason for this low amount of changes. In the interview, a considerable number of the residents showed a particular reluctance to handle the building systems and hence to make changes. In this context, the use of technology and flexibility, as a means to deal with changing needs of the residents, has not given desired results in the past. For instance, the failure of technocratic flexibility during the seventies led to flexibility in housing being criticized and being badly assessed (Loch, 2006). Therefore, the technological approach of IBA Hamburg might have contributed to the fact that residents find it difficult to make changes to their living units.

However, besides the practical reasons highlighted above, other factors that play an important role in the extent of flexibility is the economic standard of the families. This means that changing the floor plan is not always 
possible if the household's financial situation does not afford that. Another implication besides the complexity relation owner-tenant discussed above, where in most cases for any change the consent of the landlord must be obtained; building regulation implications in front of the flexibility of the building is another issue. The approval for changes, especially for external extensions, adding new openings on the facade, or even adopting new functions, requires numerous procedures, effort and energy within the building authorities; complexities in front of obtaining approval often kill the user-led flexibility (Schneider \& Till, 2007). However, unless the load-bearing interior walls are not subject to change, partition wall hangings are not an issue, as no building law denies such an action (Bundesgerichtshofes, 2000). Concerning the extensions, a new building land mobilization law that came into force in June of 2021 includes flexible handling of extensions and the expansion (Ruhmann, 2021) could pave the way for widening the application of flexibility externally.

\section{Conclusion}

The purpose of this paper is to determine the extent to which inhabitants of the "Building Exhibition within the Building Exhibition" at IBA 2013 employed flexibility in their residential buildings. A total of 22 apartments were surveyed as part of four case studies. The findings reported in the preceding section revealed that flexibility had been rarely used in these buildings over the last seven years, during which time they have been continually occupied. In light of the various reasons why flexibility is not exploited to its more significant potential, the study recommends that residents be given a more integral part of the housing process in the future. Secondly, the initial and subsequent residents should be well informed about the possibilities that flexibility offers, thereby facilitating and raising awareness of the range of changes available. Thirdly, since all of the individuals who made changes were owners rather than tenants, they should be encouraged to make changes and adapt their living space to their needs, especially when flexibility is incorporated into the building's initial concept, as it is with IBA Hamburg. When housing is incapable of accepting essential modifications, it becomes unsatisfactory or, in the worst-case scenario, obsolete (Schneider \& Till, 2007). Aside from the practical reasons, other factors that influence the extent to which flexibility is used include the family's economic status. This means that changing the floor plan is not always possible if the household's financial circumstances cannot afford it. Despite the low number of changes made even after seven years of continuous residence, a more decisive, longer duration of inhabitation will determine whether the opportunities that flexibility provides are embraced. Based on the field survey findings, we can conclude that housing flexibility is not widely used. After seven years of habitation, there was hype about the IBA Hamburg flexibility concept. However, given that this study was con- ducted after seven years of occupation, the future could be very different, for as Hellweg (2013b) stated, it is unknown whether these realized ideas will be adopted, as these concepts will require more time to prove themselves.

\section{Acknowledgements}

The author expresses his deepest gratitude and acknowledges each and every individual who has been a source of information, support and encouragement on the successful completion of this research.

\section{Conflict of interest}

The author declares no conflict of interest.

\section{References}

Braide Eriksson, A. (2016). Residential usability and social sustainability. Towards a paradigm shift within housing design? [Thesis for the degree of licentiate of Architecture]. Chalmers University of Technology.

Bundesgerichtshofes. (2000, December 21). Az. V ZB 45/0. http://juris.bundesgerichtshof.de/cgi-bin/rechtsprechung/ document.py?Gericht=bgh\&Art=en \&Datum=2000\&nr $=198$ $62 \&$ pos $=14 \&$ anz $=2206$

Chamberlain, J. (2020). Experimenting on racialized neighbourhoods: Internationale Bauausstellung Hamburg and the urban laboratory in Hamburg-Wilhelmsburg. Environment and Planning D: Society and Space, 38(4), 607-625. https://doi.org/10.1177/0263775820903328

Geipel, K. (2014). Nicht einzigartig, aber vorbildlich. In IBA Hamburg (Ed.), Stadt in der Stadt bauen (pp. 118-21). Jovis Verlag GmbH.

Gharavi Alkhansari, M. (2018). Toward a convergent model of flexibility in architecture. Journal of Architecture and Urbanism, 42(2), 120-133. https://doi.org/10.3846/jau.2018.6241

Eldonk, J. V., \& Fassbinder, H. (1990). Flexible fixation: The paradox of Dutch housing architecture. Assen.

Eckardt, F. (2017). Architecture and the "right to the city": The IBA Hamburg as a case for critical urban studies. In M. Manuela Mendes, T. Sá, \& J. Cabral (Eds.), Architecture and the social sciences. Springer. https://doi.org/10.1007/978-3-319-53477-0_9

Hacker, C., \& Lanz, M. (2013). Objekt + Produkt. "Smart ist grün” Wohnhaus für die IBA Hamburg. Detail, 2013(9), $1030-1032$.

Hamdi, N. (1990). Housing without houses: Participation, flexibility, enablement. Van Nostrand Reinhold.

Hellweg, U. (2015). Projects of IBA Hamburg from smart city to smart price - Smart material - Hybrid houses. In Warschauer Architekturgespräche. IBA GmbH.

Hellweg, U. (2013a). Stadt neu bauen. IBA Hamburg 2013. Der Sprung über die Elbe, 2013(9), 28.

Hellweg, U. (2013b). IBA Hamburg. In Housing exhibitions (pp. 162-171). DASH.

Hill, J. (2003). "Actions in architecture": Architects and creative users. Routledge. https://doi.org/10.4324/9780203327210

Institut für Bauforschung. (1980). Nachuntersuchungen an den Wettbewerbsbauten: "Flexible Wohngrundrisse" und "Elementa” Dortmund, Hamburg - Bonn, Hannover, Nürnberg. Fraunhofer IRB Verlag. 
IBA Hamburg. (2013). Der Sprung über die Elbe. IBA Spezial, 2013, 26-37.

IBA Hamburg. (2014). Stadt bauen: Stadt in der stadt bauen. Jovis Verlag $\mathrm{GmbH}$.

Jonuschat, H. (2012). Wie wollen wir in zukunft wohnen? In C. Schittich, S. Kenzen, S. Karst, \& M. Linder (Eds.), Wohnen housing (pp. 8-11). Institut für Internationale Architekturdokumentation $\mathrm{GmbH} \&$ Co. KG.

Loch, S. (2006). Life transforms living transforms life. Nordic Journal of Architectural Research, 19(3), 33-44.

Loch, S. (2011). Das adaptive habitat: Typologie und bedeutungswandel flexibler wohnmodelle [Dissertation]. Von der Fakultät Architektur und Stadtplanung der Universität Stuttgart.

Paris, S. R., \& Lopes, C. N. (2018). Housing flexibility problem: Review of recent limitations and solutions. Frontiers of Architectural Research, 7(1), 80-91.

https://doi.org/10.1016/j.foar.2017.11.004

Petersen, J. P., \& Roedel, C. (2013). Smart price house: Case study \#1. IBA Hamburg GmbH.

Petersen, J. P., \& Roedel, C. (2014). Smart material house: Woodcube. IBA Hamburg GmbH.

Raviz, S. R. H., Eteghad, A. N., Guardiola, E. U., \& Aira, A. A. (2015). Flexible housing: The role of spatial organization in achieving functional efficiency. ArchNet-IJAR: International Journal of Architectural Research, 9(2), 65-76. https://doi.org/10.26687/archnet-ijar.v9i2.422

Ruhmann, M. (2021, September). Building land mobilization law entered into force. Law is intended to promote housing construction. https://buse.de/insights/baulandmobilisierungsgesetz-in-kraft-getreten/
Salama, A. M., Wiedmann, F., \& Ibrahim, H. G. (2017). Lifestyle trends and housing typologies in emerging multicultural cities. Journal of Architecture and Urbanism, 41(4), 316-327. https://doi.org/10.3846/20297955.2017.1415773

Schneider, T., \& Till, J. (2005). Flexible housing: opportunities and limits. Architectural Research Quarterly, 9(2), 157-166. https://doi.org/10.1017/S1359135505000199

Schneider, T., \& Till, J. (2007). Flexible housing. Architectural Press.

Schoof, J. (2013). Wachstum ökologisch gestalten: Die IBA 2013 in Hamburg. Detail Green, 2013(1), 1-8.

Vallenthin, M., Paffrath, S., \& Bolland, T. (2010). Sustainable construction and housing: A needs-based approach for the future. Federal Environment Agency.

Veitch, J. A., \& Gifford, R. (1996). Choice, perceived control, and performance decrements in the physical environment. Journal of Environmental Psychology, 16, 269-276.

https://doi.org/10.1006/jevp.1996.0022

Walter, J. (2014). Neue impulse für die Hamburger stadtentwicklung. In IBA Hamburg (Ed.), Stadt in der Stadt bauen (pp. 14-17). Jovis Verlag GmbH.

Wohlin, C., \& Aurum, A. (2015). Towards a decision-making structure for selecting a research design in empirical software engineering. Empirical Software Engineering, 20, 1427-1455. https://doi.org/10.1007/s10664-014-9319-7

Wuttke, S., Junker, S., \& Winkler, S. (2018). Umsteuern erforderlich: Klimaschutz im verkehrssektor. Sachverständigenrat für Umweltfragen (SRU).

Ziller. (2020, December 16). Smart ist Grün. Lokales Energiemanagement und flexible Räume: Ein generationsübergreifendes Konzept für alle Lebensphasen. https://zillerplus.de/project/ smart/?lang=de 